\title{
The link between Tibetan Plateau monsoon and Indian summer precipitation: a linear diagnostic perspective
}

\author{
Fei Ge $\mathrm{Ge}^{1,2,3,4} \cdot$ Frank Sielmann $^{5} \cdot$ Xiuhua Zhu $^{6} \cdot$ Klaus Fraedrich $^{2} \cdot$ Xiefei Zhi $^{3,4}$. \\ Ting Peng ${ }^{3,4} \cdot$ Lei Wang ${ }^{1}$
}

Received: 30 October 2015 / Accepted: 2 February 2017 / Published online: 9 March 2017

(c) The Author(s) 2017. This article is an open access publication

\begin{abstract}
The thermal forcing of the Tibetan Plateau (TP) is analyzed to investigate the formation and variability of Tibetan Plateau Summer Monsoon (TPSM), which affects the climates of the surrounding regions, in particular the Indian summer monsoon precipitation. Dynamic composites and statistical analyses indicate that the Indian summer monsoon precipitation is less/greater than normal during the strong/weak TPSM. Strong (weak) TPSM is associated with an anomalous near surface cyclone (anticyclone) over the western part of the Tibetan Plateau, enhancing (reducing) the westerly flow along its southern flank, suppressing (favoring) the meridional flow of warm and moist air from the Indian ocean and thus cutting (providing) moisture supply for the northern part of India and its monsoonal rainfall. These results are complemented by a dynamic and thermodynamic analysis: (i) A linear thermal vorticity forcing primarily describes the influence of the asymmetric heating of TP generating an anomalous stationary wave
\end{abstract}

\section{Fei Ge}

fei.ge@mpimet.mpg.de

1 Plateau Atmosphere and Environment Key Laboratory of Sichuan Province, College of Atmospheric Sciences, Chengdu University of Information Technology, Chengdu, China

2 Max Planck Institute for Meteorology, Hamburg, Germany

3 Collaborative Innovation Center on Forecast and Evaluation of Meteorological Disasters, Nanjing University of Information Science and Technology, Nanjing, China

4 KLME, Nanjing University of Information Science and Technology, Nanjing, China

5 Meteorological Institute, Hamburg University, Hamburg, Germany

6 Hamburg University, Klima Campus, Hamburg, Germany flux. Composite analysis of anomalous stationary wave flux activity (after Plumb in J Atmos Sci 42:217-229, 1985) strongly indicate that non-orographic effects (diabatic heating and/or interaction with transient eddies) of the Tibetan Plateau contribute to the generation of an anomalous cyclone (anti-cyclone) over the western TP. (ii) Anomalous TPSM generation shows that strong TPSM years are related to the positive surface sensible heating anomalies over the eastern TP favoring the strong diabatic heating in summer. While negative TPSM years are associated with the atmospheric circulation anomalies during the preceding spring, enhancing northerly dry-cold air intrusions into TP, which may weaken the condensational heat release in the middle and upper troposphere, leading to a weaker than normal summer monsoon over the TP in summer.

Keywords Tibetan Plateau summer monsoon (TPSM) . Tibetan Plateau thermal forcing - Asymmetric influence . Indian summer monsoon rainfall

\section{Introduction}

The Tibetan Plateau (TP), with an average altitude of over $4000 \mathrm{~m}$, is the highest and most extensive geographic feature on the world (Fig. 1a). The mechanical and thermodynamic forcing and its impact on the atmospheric general circulation and the Asian monsoon systems have long been a central theme of research in the past several decades (Yeh 1950; Flohn 1957; Hoskins and Kalory 1981; Wu 1984). In addition to the regional climate effect of TP, the thermal influence of TP as an elevated heat source or sink for the large-scale atmospheric circulation has been discussed in many analyses (Yeh et al. 1957; Flohn 1968; Nitta 1983; Yanai et al. 1992; Wu and Liu 2003; Liu et al. 2004). 

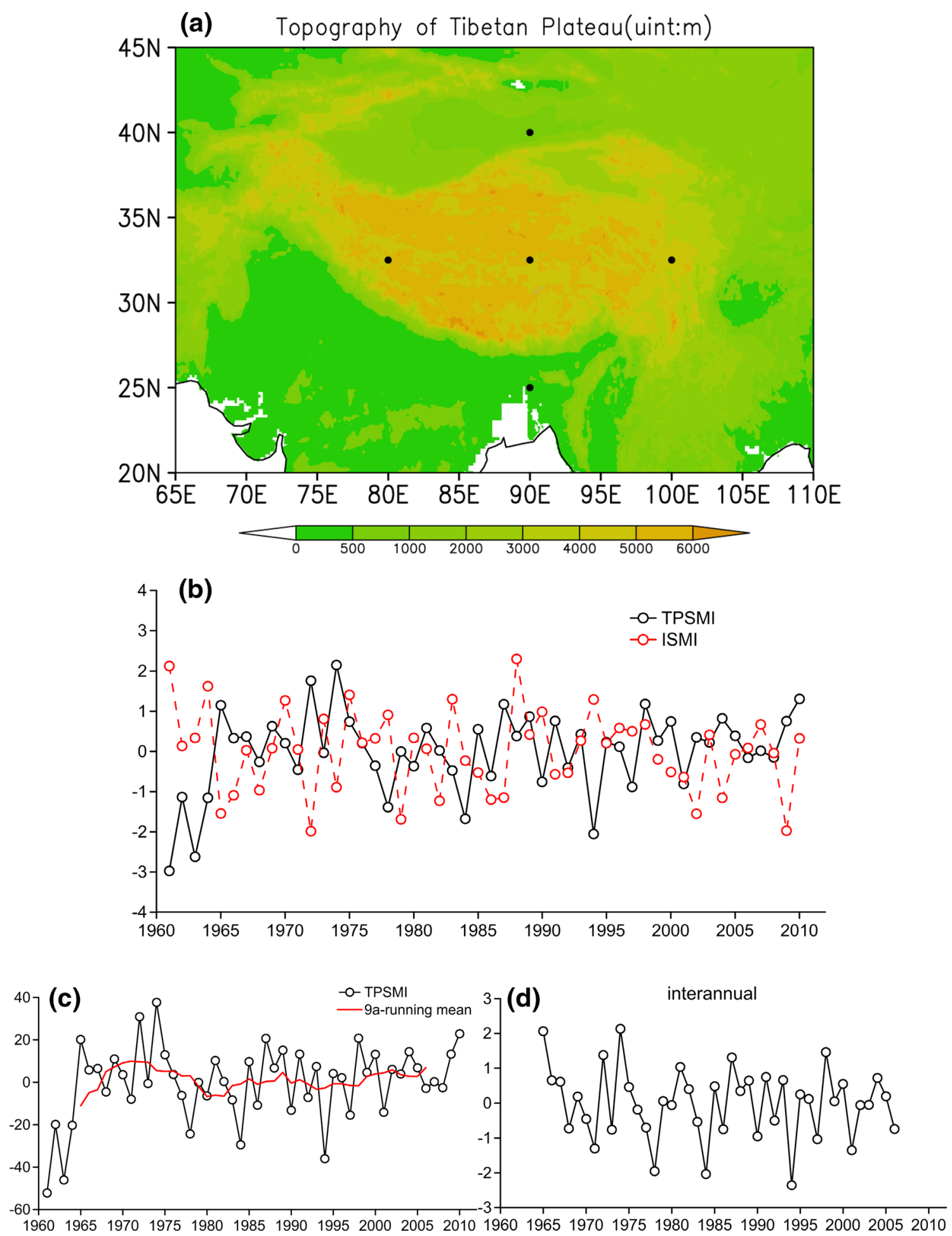

Fig. 1 a The topography of TP and the grids location for define the TPSMI (black dots). b Standardized time series of the Tibet Plateau summer monsoon index (TPSMI) and Indian summer monsoon index

Numerical experiments confirmed that the thermal forcing of TP plays an important role on the establishment and development of the Asian summer monsoon (Broccoli and
(ISMI). c Original TPSMI and 9-year running mean. d The standardized time series of the original TPSMI minus the 9-year running mean

Manabe 1992; Liu et al. 2001, 2004; Schneider and Bordoni 2008; Wu et al. 2012b; Tang et al. 2013; Chen et al. 2014). In the preceding spring season, the surface thermal 
status and its asymmetric heating over TP are well related to the onset of the Asian summer monsoon (Wu and Zhang 1998; Wu and Liu 2003; Duan and Wu 2005; Wu et al. 2007). Generally, the TP functions as a huge heat engine exhibiting direct influences on Asian monsoon variability. For example, an enhanced atmospheric heat source over the TP tends to coincide with positive precipitation anomalies over the middle and lower reaches of the Yangtze and Huaihe River precipitation and with reduced rainfall over Southeast China (Zhao and Chen 2001; Duan et al. 2005; Wang et al. 2014).

Traditionally, the Asian monsoon system consists of several sub-components, such as East Asian monsoon, South Asian monsoon and Australian monsoon. In addition, the atmospheric response to the TP-the uplifted thermal forcing establishes a topographically driven monsoon circulation, the Tibetan Plateau monsoon (TPM). Various pioneering studies have indicated that the TPM has a decisive influence on the weather and climate in the neighboring areas (Tang et al. 1979; Ye and Gao 1979; Reiter and Gao 1982; Tang and Reiter 1984; Tian et al. 2001). (i) Circulation: it is well known that there also exists a cyclonic circulation around the TP during the summer season, which changes to an anti-cyclonic circulation in winter. Observations show that the TPM is the dynamic link between Tibetan snow cover and the Indian summer monsoon rainfall. (ii) Precipitation: recent research has shown that the TPM has different influences on precipitation over Tibetan Plateau and its vicinity. For example, a strong Tibetan Plateau summer monsoon (TPSM) can significantly influence the rainfall distribution over TP and northwest China (Liu 1999; Bai et al. 2005). Bai and Li (2015) suggest that the seasonal advance of the rain belt over TP corresponds to the transitions between the summer and winter TPM. The east-west spatial correlation between Tibetan snow cover and the Indian summer monsoon rainfall changes in sign around 1985, and attributes to the transition from a weak to a strong TPM (Kripalani and Kulkarni 1999; Saito et al. 2004; Zhao and Moore 2004). (iii) Variability: Analyzing the precipitation (1961-2010, 39 meteorological stations) in the Tarim River Basin indicate a trend from dryer towards wetter conditions after the middle of the 1980s (Borth et al. 2016; Tao et al. 2016). Zhao et al. (2015) examining the relationship between TPSM and the precipitation over Tarim Basin (northwest of TP) show that the anomalous anticyclone in the upper troposphere is associated with the strong TPSM transporting cold air from high latitudes into the western part of TP and southerly winds intensifying east of the cooling region. Thus, the summer precipitation increases over the Tarim Basin. Overall, both dynamic and thermodynamic features of TP are important for the regional and global climate. This issue remains a scientific challenge and concern.
In this paper, our analyses are focused on the asymmetric thermal heating over TP during strong and weak TPSM years, with the aim to explore possible clues which establish the TPSM and to account for its variability. The paper is organized as follows: datasets and methods of analysis are described in Sect. 2. The interannual variability of precipitation associated with TPSM is shown in Sect. 3. Also in this section, we present the asymmetric heating over TP during the strong and weak TPSM years, its association with TPSM in the preceding season. Finally, the conclusions and further discussion are provided in Sect. 4.

\section{Data and methods}

\subsection{Data}

A high-resolution precipitation field (CRU TS3.1) is obtained from Climatic Research Unit (CRU) (Mitchell and Jones 2005; Harris et al. 2014) for the period of 1961-2010 is employed to investigate the relationship between TPSM and Indian summer precipitation. For lack of enough observations and long-term data over TP, the analysis of TP thermal impact on the global climate is often a difficult task, particularly on the surface heat flux. In this paper, the National Centers for Environment Prediction/ National Center for Atmospheric Research (NCEP/NCAR) reanalysis and Twentieth Century Re-Analysis Project for the period of 1961-2010 are used to reveal the large scale atmospheric circulation anomalies and total atmospheric diabatic heating patterns (Kalnay et al. 1996; Whitaker et al. 2004; Compo et al. 2006). These reanalysis datasets for examining thermal status over TP (such as sensible heating, radiative and latent heating) has been validated by many previous studies (Liu et al. 2001; Duan and Wu 2008; Wu et al. 2012a, 2016). Note that the long-term linear trends in all datasets have been removed.

\subsection{Methods}

To investigate the spatial and temporal variability of TPSM and its association with the Indian summer rainfall, two monsoon indices are used in this study which is introduced as follows:

The Indian summer monsoon index (ISMI) is defined by the averaged total rainfall (JJAS) over the Indian subcontinent (Parthasarathy et al. 1992, 1993). Here, we use the geopotential height anomaly (JJA) at $600 \mathrm{hPa}$ to define a Tibetan Plateau summer monsoon index (TPSMI), with larger (smaller) values representing stronger (weaker) summer monsoon over TP (Tang and Reiter 1984). The grids used to define the TPSMI are shown in Fig. 1a. 
According to Yanai et al. (1973) and Yanai and Li (1994), the apparent heat source (Q1) and moisture sink (Q2) are used to calculated by

$$
\begin{aligned}
\mathrm{TPSMI}= & \mathrm{H}\left(32.5^{\circ} \mathrm{N}, 80^{\circ} \mathrm{E}\right)+\mathrm{H}\left(32.5^{\circ} \mathrm{N}, 100^{\circ} \mathrm{E}\right)+\mathrm{H}\left(25^{\circ} \mathrm{N}, 90^{\circ} \mathrm{E}\right) \\
& +\mathrm{H}\left(40^{\circ} \mathrm{N}, 90^{\circ} \mathrm{E}\right)-4 \mathrm{H}\left(32.5^{\circ} \mathrm{N}, 90^{\circ} \mathrm{E}\right)
\end{aligned}
$$$$
Q_{1}=C_{p}\left(\frac{p}{p_{0}}\right)^{k}\left[\frac{\partial \theta}{\partial t}+\vec{V} \cdot \nabla \theta+\omega \frac{\partial \theta}{\partial p}\right]=Q_{R}+L(c-e)-\frac{\partial\left(\overline{s^{\prime} \omega^{\prime}}\right)}{\partial p}
$$

$$
Q_{2}=-L\left(\frac{\partial q}{\partial t}+\vec{V} \cdot \nabla q+\omega \frac{\partial q}{\partial p}\right)=L(c-e)+L \frac{\partial\left(\overline{q^{\prime} \omega^{\prime}}\right)}{\partial p}
$$

where $\theta$ is the potential temperature, $q$ the mixing ratio of water vapor, $V$ the horizontal wind, $\omega$ the vertical $p$-velocity, $k=R / C_{p}, R$ and $C_{p}$ are the gas constant and the specific heat at constant pressure of dry air, $L$ the latent heat, $p_{0}=1000 h P a, Q_{R}$ the radiative heating rate, $s=c_{p} T+g z$ the dry static energy, $c$ the rate of condensation per unit mass of air and $e$ the rate of re-evaporation of cloud and rain water. When examining the statistical significance of the correlation and composite analysis, the effective number of degrees of freedom is considered according to Davis (1976). All statistical significance tests for correlations are analyzed employing the two-tailed Student's $t$ test.

\section{Results}

The complex surface topography and the remarkable altitude difference between the eastern and western part of TP, may cause the asymmetric thermal heating on the TPM. Although most of previous studies have been focusing on the heating effect of the TP, the following questions are still open: (1) How do interannual variations of TPSM influence the Indian monsoon precipitation? (2) What are the predominant processes in the preceding season favoring TPSM? (3) How is the TPSM associated with the diabatic thermal heating? These issues are discussed in the following sections.

\subsection{Interannual variations of precipitation associated TPSM}

The time series of the TPSMI and ISMI shown for the period from 1961 to 2010 (Fig. 1b). The correlation of TPSMI with ISMI is -0.44 , satisfying a $95 \%$ confidence level. This indicates that the year-to-year TPSM variations are closely related with the Indian summer monsoon. In contrary, the correlation of TPSMI with Nino3.4 index is only -0.029 , indicating that the impact of ENSO is week.
By removing the interdecadal signals (9-year running mean) from the original TPSMI (Fig. 1c, d), the interannual variability of TPSM, can be grouped into anomalous strong/weak years between 1961 and 2010 by selecting TPSMI anomalies exceeding \pm 1 standard deviation. This yields six positive (strong) years $(1965,1972,1974,1981$, 1987 and 1998) and six negative (weak) years (1971, 1978, 1984, 1994, 1997 and 2001), which are composited to examine the anomalous precipitation associated with strong and weak TPSM. The composite analyses show the following results: summer precipitation anomalies during positive (negative) TPSM years (Fig. 2a, b) are less (more) intense than normal over the northern part of India and Indochina Peninsula. The difference shows that significant positive anomalies occur in the western and northern part of TP and while negative anomalies predominantly appear in northern India (Fig. 2c). That is, TPSM-variations appear to modulate northern Indian precipitation. In the following sections, the modulating mechanism is elucidated by analyzing the regional atmospheric circulation and the diabatic heating anomalies during strong and weak TPSM years.

\subsection{Anomalous atmospheric circulation links to the TPSM}

Wind field composites of strong (weak) TPSM years are characterized by a cyclonic (anti-cyclonic) circulation anomaly over the TP surface (500 hPa, Fig. 3a, b). Compared with the climatological mean flow, the northern part of India is dominated by enhanced westerlies (easterlies) associated with the cyclonic (anti-cyclonic) flow anomaly, which is shared by the vertically integrated water vapor flux composites (Fig. 3c, d). The composite stationary wave activity flux (WAF) anomalies based on the formula of Plumb (1985) are displayed in Fig. 3e, f. The WAF anomalies at $300 \mathrm{hPa}$ provide some insights into the quasistationary wave propagation during strong (weak) TPSM years. The corresponding positive (negative) quasi-geostrophic stream function fields illustrate that the cyclonic (anti-cyclonic) circulation also occur at upper level over $\mathrm{TP}$, which are consistent with the wind field composites at $300 \mathrm{hPa}$ (not shown). Note that the cyclonic (anti-cyclonic) circulation appear over the western part rather than over the central of TP at both lower and upper level, revealing an anomalous retrograde propagation of stationary wave energy over TP. In summarizing: summer precipitation over northern India is influenced by the anomalous atmospheric circulation associated with the TPSM variability.

(i) During the strong TPSM years, a reduced summer monsoon precipitation over northern India can, therefore, be explained by anomalous westerlies along the southern flank of the extended and enhanced Tibetan 
(a)

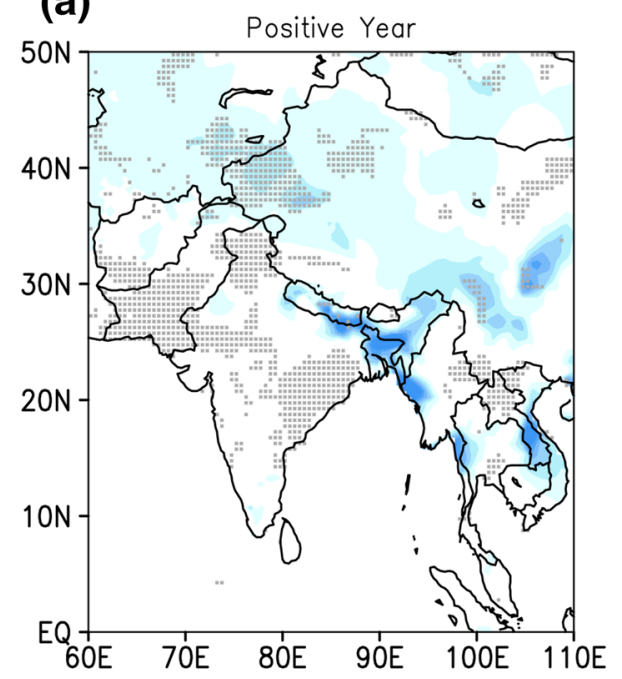

(b)

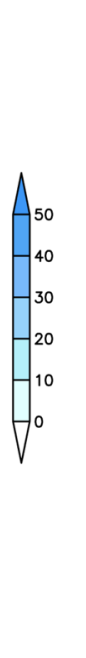

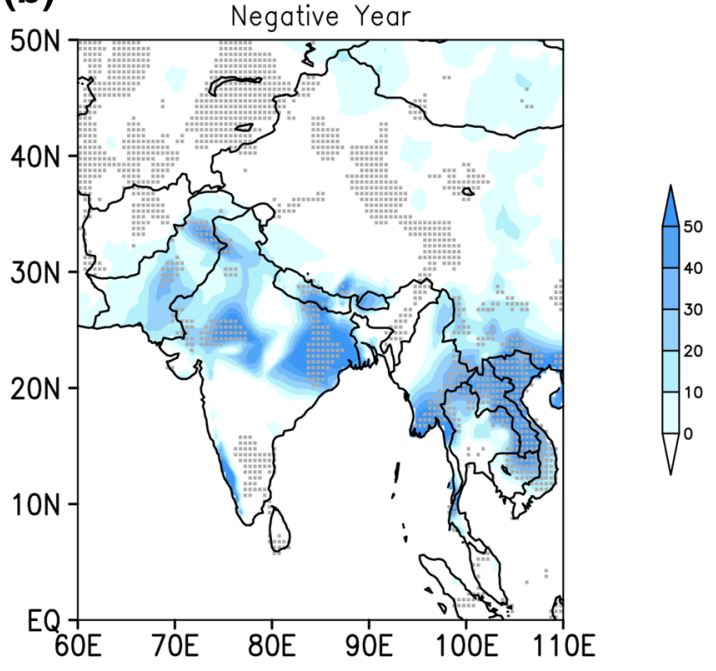

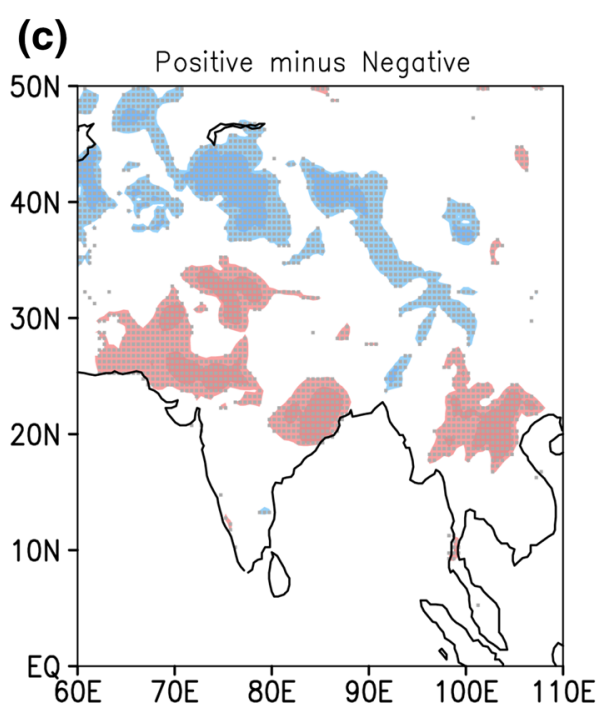

Fig. 2 Composites of seasonal precipitation anomalies in JJA during the positive and negative anomalous years (unit: in mm per season): a positive year, b negative year, and c positive minus negative year (grey dots indicate statistically significant at the $95 \%$ confidence level)

Plateau cyclone. And, due to the associated anomalous anticyclone over central India, the moisture import from the southwest (Arab Sea) is suppressed by the easterlies along the southern flank of the anticyclone.

(ii) During the weak TPSM years, a reversed pattern occurs over India and TP. The increased summer monsoon precipitation over northern India which can be explained by anomalous easterlies along the southern flank of the extended and enhanced Tibetan Plateau anticyclone. And, the central Indian cyclonic flow steers the moisture transporting from the southwest via the Bay of Bengal to northern India.

\subsection{Diabatic heating asymmetry during strong and weak TPSM years}

Over centuries the major role of the Tibetan plateau on the generation of stationary waves by orographic vorticity forcing is well known. Secondly, the TP has been regarded as an elevated heating source in boreal summer exerting significant impact on the large-scale atmospheric circulation. It implies that the thermal heating status over TP is closely related to the circulation and rainfall over its surrounding areas. To further illustrate the effects of the TPSM on the anomalous atmospheric circulation, we first show the 


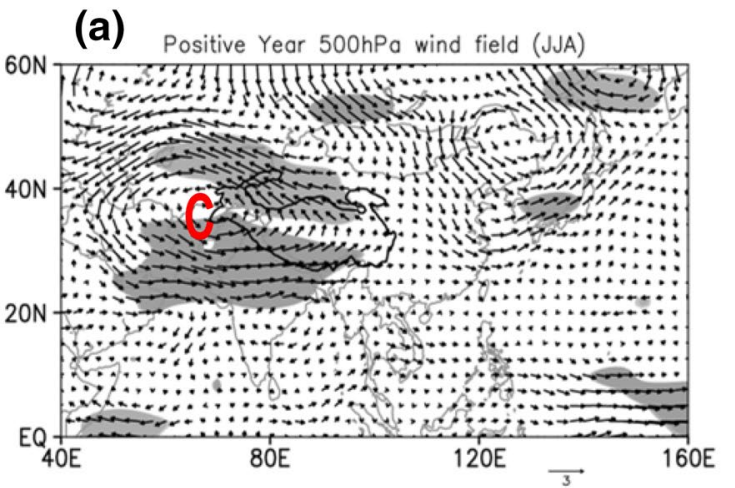

(c) Positive year integral of water vapour flux (JJA)

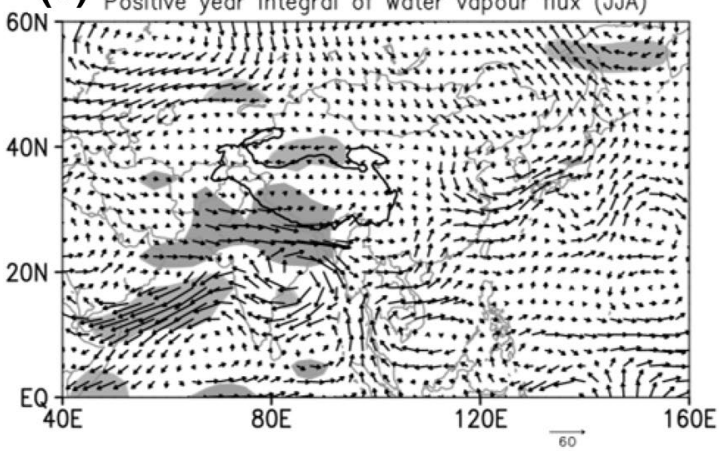

(e) WAF composite anomalies positive years (JJA)

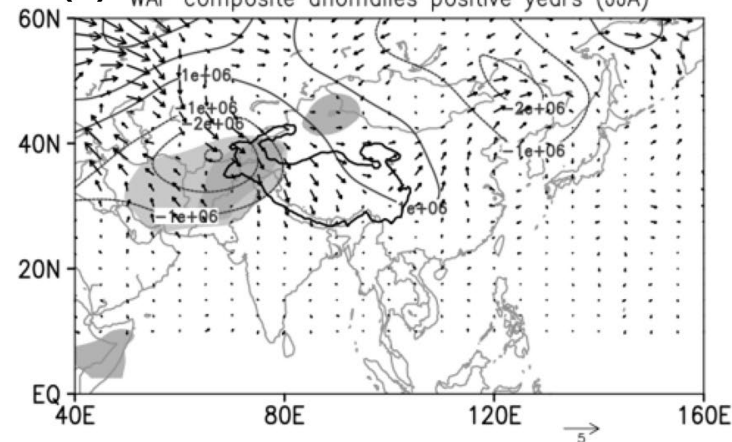

Fig. 3 The composite wind field anomalies $(\mathrm{m} / \mathrm{s})$, vertical integral of moisture flux anomalies $[\mathrm{kg} /(\mathrm{m} \mathrm{s})]$ and Plumb's stationary wave flux anomalies $\left(\mathrm{m}^{2} / \mathrm{s}^{2}\right.$, arrows; contours: QG stream function) at $300 \mathrm{hPa}$

apparent heat source $\left\langle Q_{1}\right\rangle$ and moisture sink, $\left\langle Q_{2}\right\rangle$ anomalies in Fig. 4. The following results are obtained:

(i) The strong TPSM years show positive diabatic heatingatmosphere the quasi-geostrophic $\left\langle Q_{1}\right\rangle$ anomalies, which appear over the eastern and northwestern part of the TP, while the negative heating anomalies $\left\langle Q_{1}\right\rangle$ occur over the central TP and northern India (Fig. 4a). Positive moisture sink anomalies $\left\langle Q_{2}\right\rangle$ are dominating over the eastern and northern part of TP and negative $\left\langle Q_{2}\right\rangle$ anomalies appear over the Himalaya and northern India (Fig. 4c). (b) Negative Year $500 \mathrm{hPa}$ wind field (JJA)

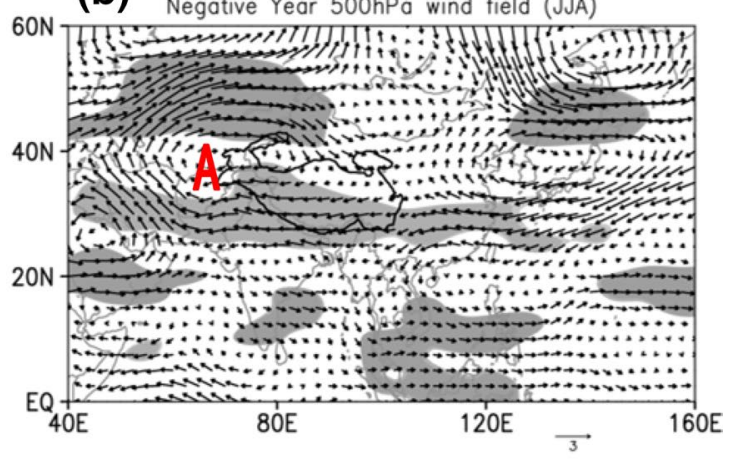

(d) Negative year integral of water vapour flux (JJA)

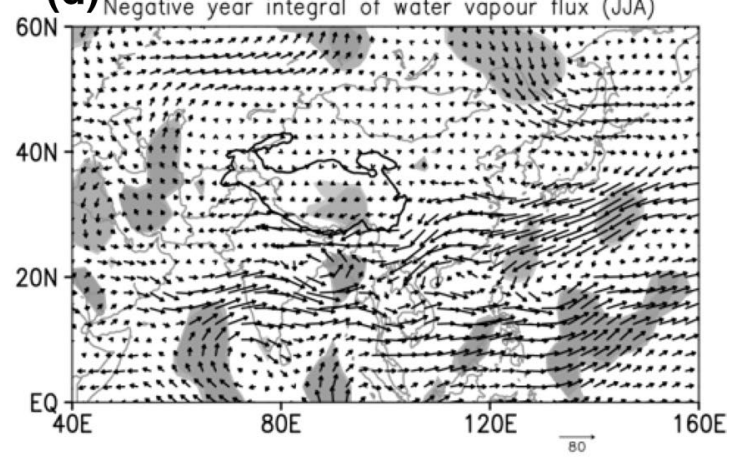

(f) WAF composite anomalies negative years (JUA)

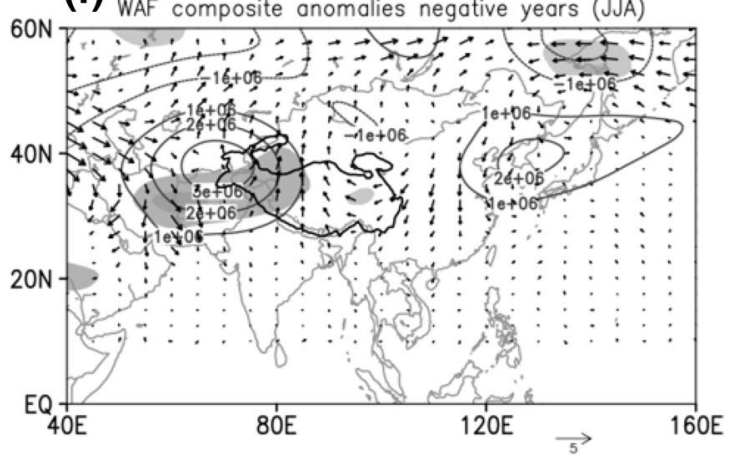

during strong and weak TPSM years. Shaded areas are statistically significant at the $95 \%$ confidence level. The solid curve indicates where the elevation exceeds $3000 \mathrm{~m}$

(ii) In weak TPSM years, positive $\left\langle Q_{1}\right\rangle$ anomalies exist almost only over the Indian subcontinent (Fig. 4b), while the negative $\left\langle Q_{1}\right\rangle$ heating anomalies are primarily located over the TP. Positive $\left\langle Q_{2}\right\rangle$ anomalies are predominantly over the India and negative $\left\langle Q_{2}\right\rangle$ anomalies occur over TP (Fig. 4d).

(iii) The difference of strong-minus-weak TPSM composites show spatial distributions of the $\left\langle Q_{1}\right\rangle$ and $\left\langle Q_{2}\right\rangle$-fields (see Fig. 4e, f), which reveal a dipolelike pattern connecting the eastern part of TP and northern India. This indicates that the eastern part of TP is more sensitive to diabatic heating and the asym- 

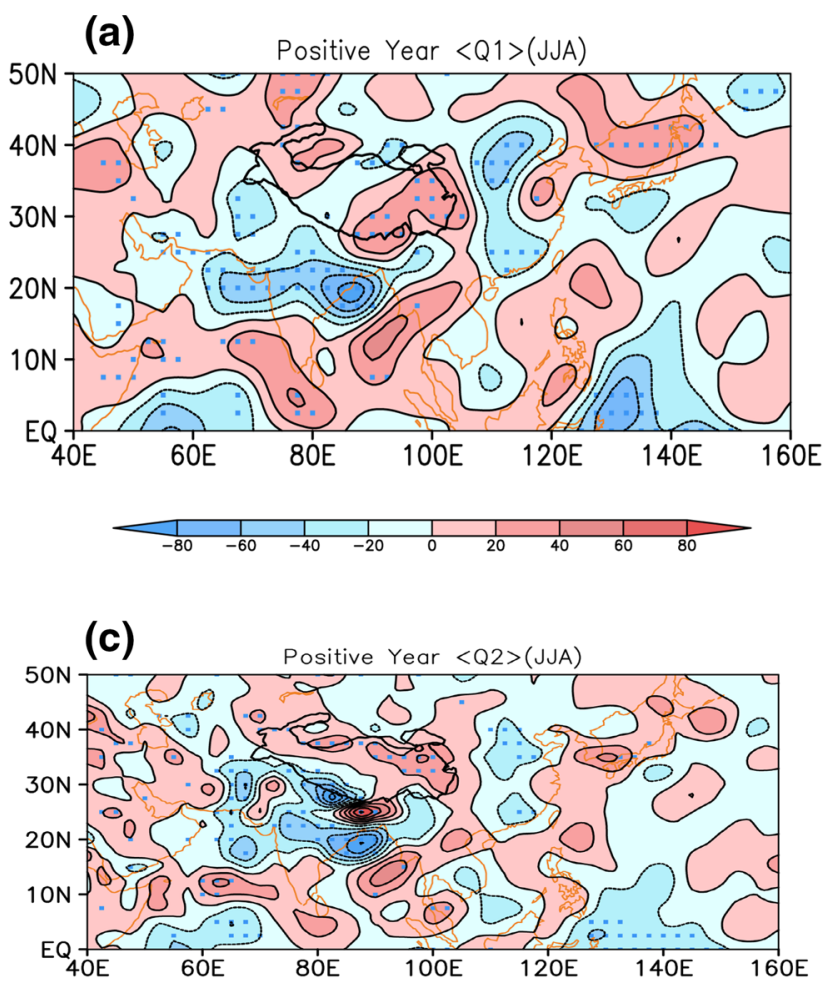

(e)

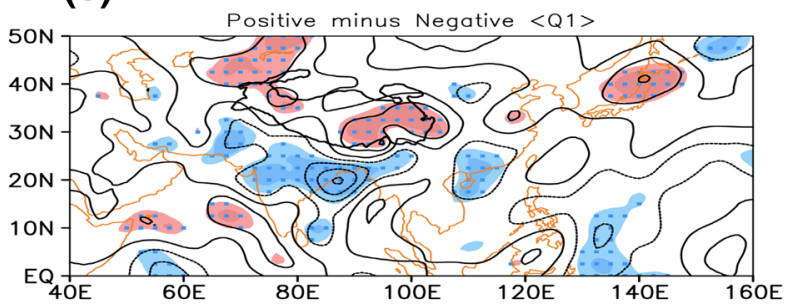

Fig. 4 The vertical integral of $\left\langle Q_{1}\right\rangle$ and $\left\langle Q_{2}\right\rangle$ anomalies (contour interval 20) in strong (weak) TPSM years (a-d). The difference between positive and negative years (e-f). Blue dots indicate statisti-

metry of this anomalous heating between TP and northern India may have impact on the atmospheric circulation associated with the TPSM.

Over the Tibetan plateau, strong (weak) TPSM is associated with anomalous cyclonic (anti-cyclonic) vertically averaged (column) vorticity $\langle\zeta\rangle$, which is induced by the diabatic heating anomalies $\left\langle Q_{1}\right\rangle$ and the associated thickness change. That is, the thermal vorticity change $\Delta\langle\zeta\rangle$ as a function of $\left\langle Q_{1}\right\rangle$ and time interval $\Delta t$, $\Delta\langle\zeta\rangle=f\left(\left\langle Q_{1}, \Delta t\right\rangle\right)$ is derived as follows:

For the barotropic atmosphere the quasi-geostrophic vorticity equation for a homogenous fluid of variable depth $h(x$, $y$ ), an upper boundary at a fixed height $H$, and a forcing by a
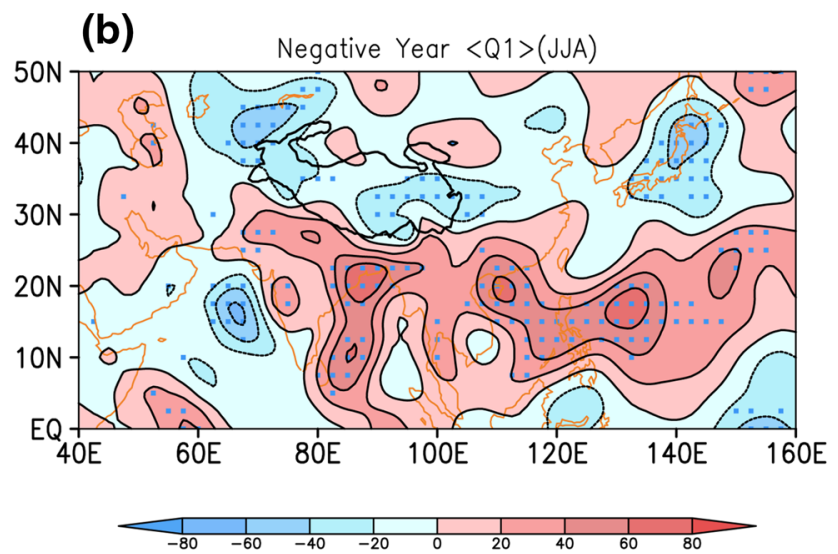

(d)
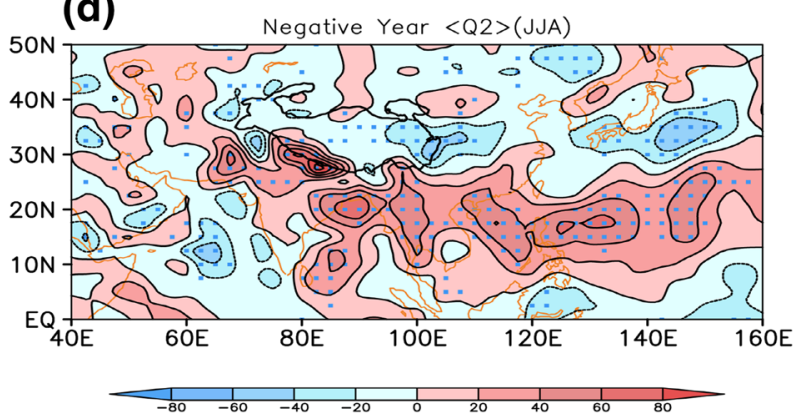

(f)

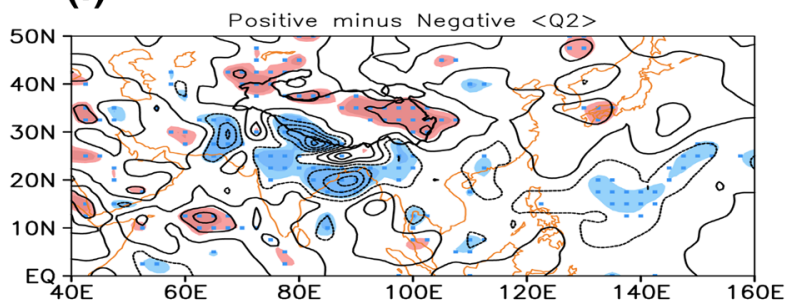

cally significant at the $95 \%$ confidence level, contour interval 40 . The solid curve indicates where the elevation exceeds $3000 \mathrm{~m}$

longitudinally dependent diabatic heating pattern, we formulate for the vorticity anomaly (following Holton 1992).

$\frac{d(\xi g+\mathrm{f})}{d t}=-\frac{\mathrm{f}_{0}}{H} \frac{d h}{d t}$

Interpreting the right hand side as forcing by longitudinally dependent diabatic heating patterns, we can formulate the vorticity forcing (right hand side) by further applying the quasi-geostrophic scaling $\left|\xi_{g}\right| \ll \mathrm{f}_{0}$ and by omitting the local change $\frac{\partial \xi}{\partial t}$ :

$\frac{d \zeta}{d t}=-\frac{\mathrm{f}_{0}}{g H} u \cdot \frac{\partial \Phi}{\partial x}$ 
With introducing the definition of the relative topography $g \Delta_{h}(\Delta \mathrm{z})=\Delta_{h}(\Delta \Phi)=R \Delta_{h} T_{m} \ln \left(P_{2} / P_{1}\right)$ (subscript $\mathrm{h}$ is indicating the horizontal change), using the relation $\nabla\left\langle Q_{1}\right\rangle=\nabla T_{m} C_{p}$ with $\left\langle Q_{1}\right\rangle$ the vertically integrated apparent heat source of the thermodynamic energy equation (Eq. 1) and $T_{m}$ the mean temperature of the air column, and assuming that an advected air volume adiabatically follows the level of constant potential (or absolute) vorticity, thereby squeezing or stretching its isohypses by $\Delta \Phi=H-h$, we obtain the thermal vorticity forcing equation.

$\frac{\partial \zeta}{\partial t}=f_{0} * R /\left(C_{p} H g^{2}\right) \ln \left(P_{2} / P_{1}\right) \vec{v} \cdot \nabla\left\langle Q_{1}\right\rangle$

where $H$ is the scale height and $R$ is the gas constant. The other parameters are identical to those introduced in Eq. 1. Note, that the purely longitudinal dependency of the heating pattern is replaced by a 2-dimensional horizontal one, which makes almost no difference in the results due to the normally weaker meridional flow anomalies.

The thermal vorticity forcing (right hand side of Eq. 5) composites of strong (weak) TPSM years are shown in Fig. 5a-c with the $P_{1}, P_{2}$ are $150,500 \mathrm{hPa}$, respectively, which reveal a reversed pattern during the strong (weak) TPSM years. The negative forcing appears over central TP and northern Himalayan ridge and the positive forcing exists over the northwestern of TP and northern India in the strong years (Fig. 5a), whereas in weak TPSM years negative forcing appears over western TP and northern Himalayan ridge and positive forcing exists over the northern India (Fig. 5b). Especially (Fig. 5c), the difference of strong-minus-weak composites reveal a tripole-like pattern over TP and northern India. That is, the anomalous cyclonic (anticyclonic) circulation is primarily modulated by anomalous thermal vorticity forcing over the western of TP and northern Himalaya. Actually, the relative warming (cooling)

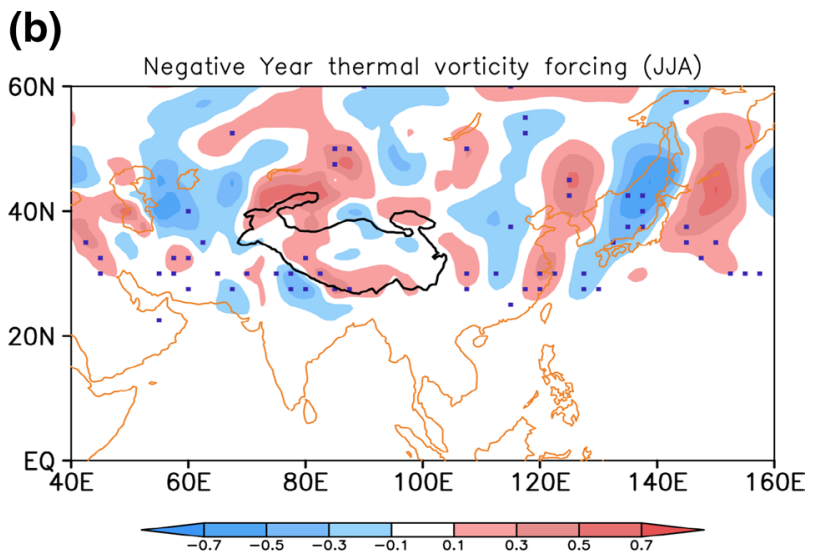

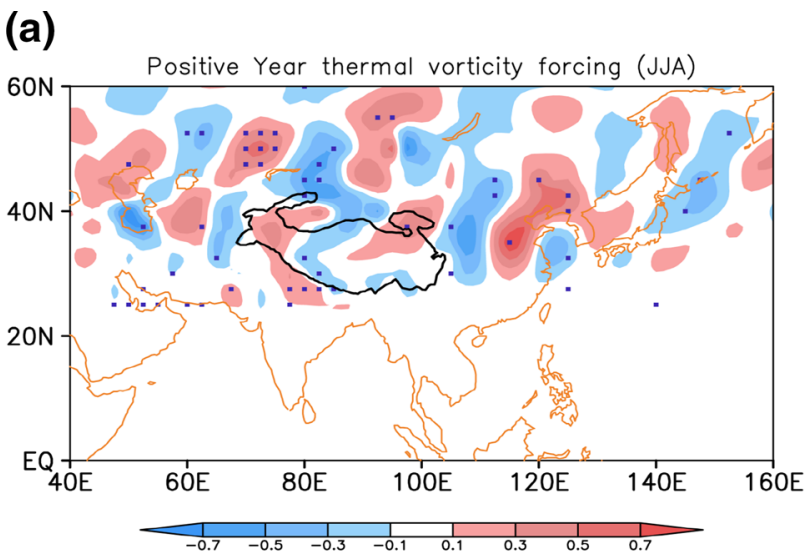

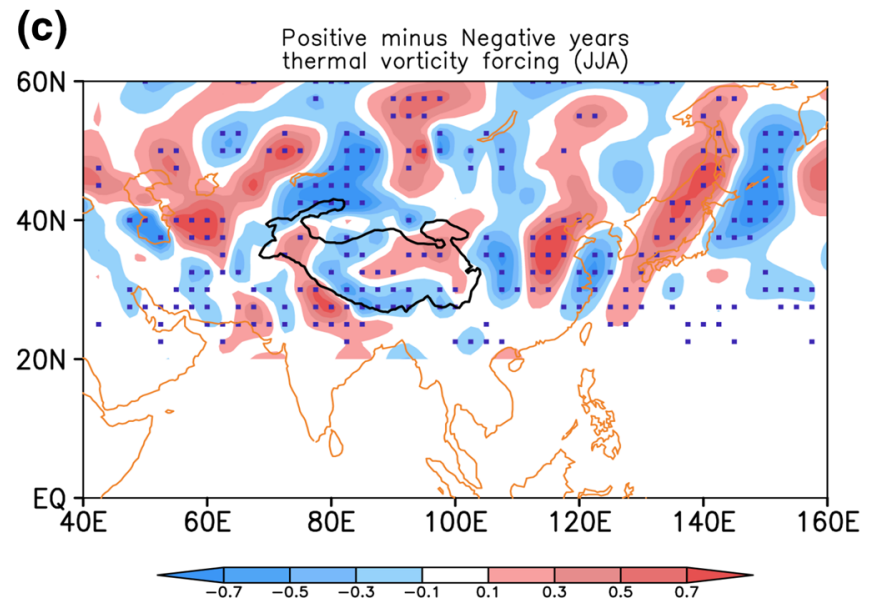

Fig. 5 The thermal vorticity forcing $\left(10^{-10} \mathrm{~s}^{-2}\right)$ anomalies in strong and weak TPSM years (a, b). The difference between positive and negative years (c). Dark blue dots indicate statistically significant at the $90 \%$ confidence level, contour interval 0.1 . Maskout regions: $0-20^{\circ} \mathrm{N}$. The solid curve indicates where the elevation exceeds $3000 \mathrm{~m}$ 
TP (see the Fig. 4a, b) in strong (weak) TPSM years acts as an elevated (lowered) topography, associated with strengthening (weakening) of the subtropical jet upstream of TP and the vertical gradient of zonal wind velocity (see Fig. 5 from Park et al. 2013). That is, the TP diabatic heating (cooling) induces a wavenumber 4-6 stationary forcing pattern with a localized cyclone (anticyclone) upstream of the diabatic forcing in the same manner as a lowered (elevated) topography would do. The reverse applies to the downstream flow. Thus, the westward stationary wave propagation, induced by the anomalous heating over TP, leads to cyclonic (anticyclonic) anomalous circulation upstream propagating out of the heating (strong TPSMI)/cooling (weak TPSMI) regions.

The asymmetric diabatic heating over TP and its pattern changing during strong and weak TPSM years may be related to different p-velocity anomalies $\omega$. This is shown in Fig. 6a-d, with positive (negative) values representing descending (ascending) motion. During strong TPSM years (Fig. 6a, b), anomalous ascending motions with higher values over the western TP, is separated (by the Himalaya) from the descending motion over northern India. The vertically integrated divergence of moisture flux anomalies (Fig. 6e-f) shows a remarkable convergence over the TP for strong TPSM. The intensified convergence and the anomalous southerlies result in above-normal rainfall over the TP. In contrast, enhanced moisture divergence associated with anomalous dry continental westerlies reduces precipitation over northern India (Fig. 6e). During weak TPSM years, this situation is reversed. The anomalous descending motion appears over the TP, especially pronounced over its eastern part. The corresponding ascending motions occur primarily over northern India (Fig. 6c, d). With increasing elevation, the upward motion increases gradually. Anomalous water vapor flux convergence, originating from the Bay of Bengal, results in above-normal rainfall observed over northern India, while enhanced divergence causes decreasing precipitation over the TP (Fig. 6f).

Besides the thermal (sensible and latent heat) forcing in summer, the preceding season's thermal forcing can also influence the atmospheric circulation. Results of numerical studies suggested that stronger (weaker) sensible/latent heat fluxes correspond to higher (lower) soil temperature as well as less (more) soil moisture, thereby extending the direct spring influences into summer (Wu and Zhang 1998; Duan et al. 2005). Therefore, we examine the surface diabatic heating in the preceding season in order to explain the possible clues of the generation of TPSM in the following section.

\subsection{Relating the anomalous TPSM to the preceding spring season}

The composite dynamical flow patterns, which are associated with the strong and weak TPSM in preceding spring, highlight the external influences of cold air from high latitudes (Fig. 7). The following results are noted:

(i) The spring season (MAM) preceding strong monsoon years is characterized by cold air flow from the northeast, which is associated with the Mongolian anticyclone, occurs north of the northern edge of the TP (Fig. 7a). That is, most of the TP is affected by these easterly anomalies combined with easterlies from the West Pacific transporting abundant warm and moist air into the plateau.

(ii) The spring season (MAM) preceding weak monsoon years is characterized by a westward shifted Mongolian anticyclone (Fig. 7b). Northeasterly winds along the eastern flank of the Mongolian anticyclone import colder air from higher latitudes, which contributes to the middle and upper level cooling over TP.

The difference of latent and sensible heating (LH and $\mathrm{SH}$ ) and the vertically integrated horizontal temperature advection anomalies are shown in Fig. 8. To highlighton interannual time scale-the difference of asymmetric heating patterns in the preceding spring season, variations longer than 10 years are filtered out by a Fourier filter. The strong-minus-weak TPSM composites show that the asymmetric diabatic heating has already onset over the western and eastern part of TP during the preceding season. The significant positive LH anomalies appear over the central and western TP in the preceding winter (Fig. 8a), while the negative anomalies occur over the central TP in the preceding spring (Fig. 8b). In contrast, the negative $\mathrm{SH}$ anomalies predominantly appear over the central and western TP in the preceding winter (Fig. 8c), whereas the positive $\mathrm{SH}$ anomalies dominate over the central and eastern TP in the preceding spring (Fig. 8d). The diabatic heating $Q_{1}$ is balanced by the three terms of the thermodynamic energy Eq. (1): local change, horizontal and vertical advection. The difference of integrated horizontal temperature advection anomalies are shown in Fig. 8e, f: Positive anomalies are observed over the north and central plateau during the preceding winter, while in the preceding spring, the positive anomalies occur over the eastern part of TP and negative anomalies over western part. Further results are noted:

(i) The spring seasons (MAM) preceding strong monsoon years are characterized by positive $\mathrm{SH}$ over the eastern TP (Fig. 8d), with stronger heating of the dryer surface. Meanwhile, the LH flux anomalies are also positive at 


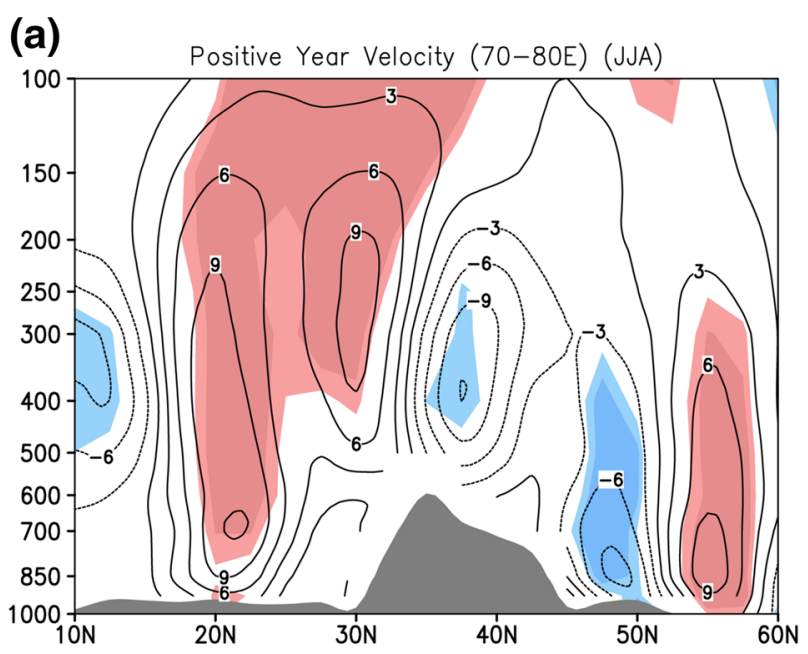

(b)

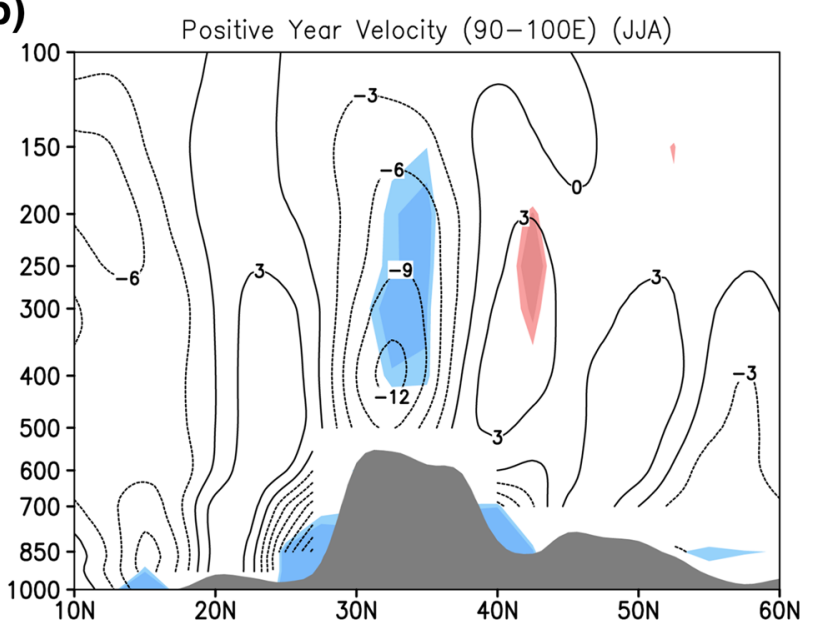

(c)

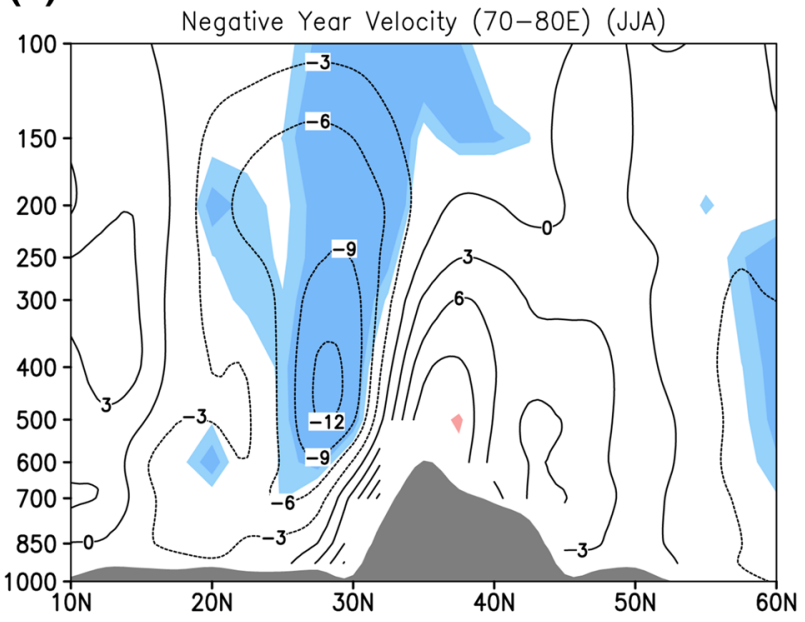

(d)

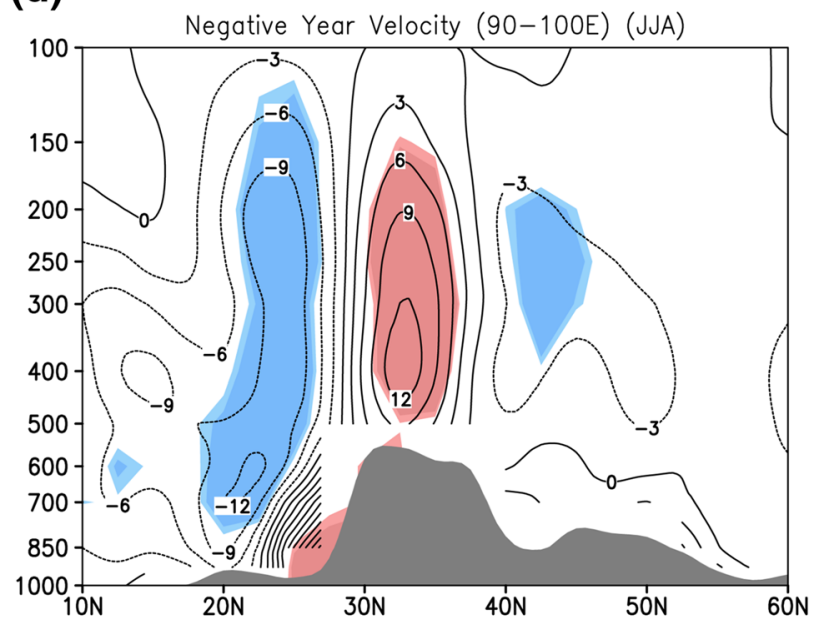

(e)

(f)
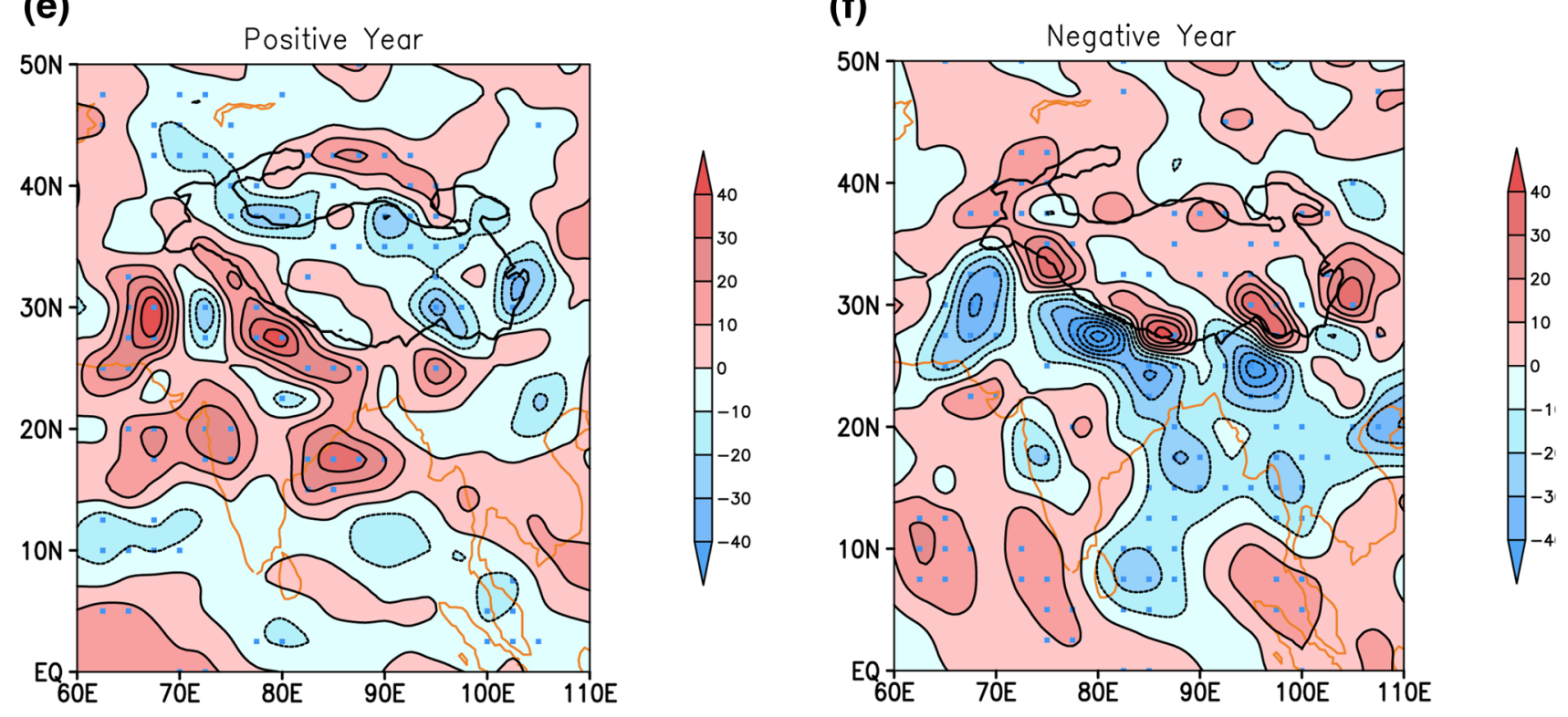
4Fig. 6 As in Fig. 5 but for the vertical velocity $\left(10^{3} \mathrm{~Pa} / \mathrm{s}\right)(\mathbf{a}-\mathbf{d})$ and the vertical integral of divergence of moisture flux $\left(10^{-6} \mathrm{~kg} \mathrm{~m}^{-2} \mathrm{~s}^{-1}\right)$ anomalies (contour interval 10) during strong and weak TPSM years, shaded areas $(\mathbf{a}-\mathbf{d})$ and blue dots $(\mathbf{e}-\mathbf{f})$ indicate statistically significant at the $90 \%$ confidence level, respectively. The solid curve indicates where the elevation exceeds $3000 \mathrm{~m}$

the eastern edge of the $\mathrm{TP}\left(90^{\circ}\right.$ to $\left.100^{\circ} \mathrm{E}\right)$, where the integrated horizontal temperature advection is also higher (over eastern TP, Fig. 8f). The cold air advection associated with the Mongolian anticyclone only occurs north of the northern edge of the TP (Fig. 7a). That means that positive sensible and latent heating anomalies $(d S H>0, d L H>0)$ over the eastern TP in conjunction with humid easterlies from West Pacific play a main role in the spring season preceding strong TPSM years as they support enhanced diabatic heating

$\left\langle Q_{1}\right\rangle$ in summer which, in turn, may be linked to a stronger TPSM.

(ii) In contrast, the dry and colder air associated with the westward shift of the Mongolian anticyclone (Fig. 7b) leads to less condensational heat release $(d L H<0)$ into the atmospheric column in the preceding spring season (MAM) which, when cooling the surface over the TP $(d S H<0)$, suppresses the diabatic heating $\left\langle Q_{1}\right\rangle$ in summer. Consequently, it may relate to weaker-than-normal monsoon seasons over the TP.

\section{Conclusion and discussion}

The Indian summer monsoon precipitation can be related to strong versus weak Tibetan Plateau Summer Monsoon (TPSM) and its preceding spring season. The following results are obtained and comprised in a schematic diagram (Fig. 9).

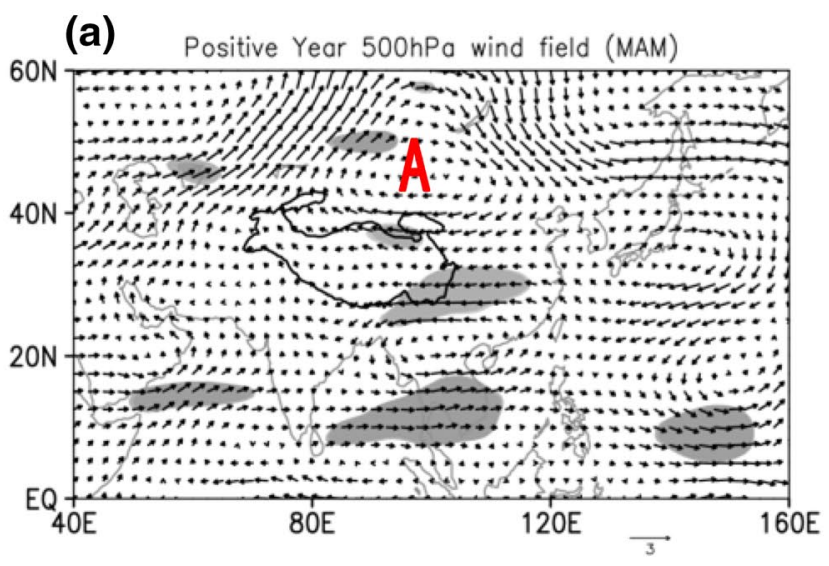

(i) The rainfall is less (more) intense than normal over the North of India during strong (weak) TPSM years, which is associated with an anomalous near surface cyclone (anticyclone) over the western part of the TP. The central Indian (anti-cyclonic) cyclonic flow reduces (enhances) the warm and moist air transporting from the ocean to northern India (Fig. 9a, b). These major anomalous steering centers are induced by stationary waves (wavenumber 4-6), which originate from the diabatic heating anomalies over TP. Positive (negative) anomalies induce cyclonic (anti-cyclonic) vorticity upstream of the heating.

(ii) The anomalous thermal vorticity forcing is significantly influenced by the asymmetric heating of TP. Westward cyclonic (anticyclonic) vorticity anomalies during strong (weak) TPSM years are associated with the anomalous thermal vorticity forcing over western TP and the northern Himalayan ridge, leading to cyclonic (anticyclonic) circulations upstream the heating (cooling) region.

(iii) During spring seasons preceding strong TPSM summers, the positive SH anomalies over the eastern part of the TP lead to the strong ascending motion which favor, due to enhanced condensational heat release, rising temperatures in the mid-troposphere. Cold air advection, is induced by the Mongolian anticyclone which occurs only north of the northern edge of the TP. Meanwhile, easterly anomalies from the West Pacific transport sufficient warm air into the plateau. That is, the persistent $\mathrm{SH}$ and $\mathrm{LH}$ in conjunction with humid easterlies from West Pacific favor a strong TPSM (Fig. 9c).

(iv) During spring season preceding weak TPSM summers, cold air intrusion from higher latitudes reduce condensational heat release as northeasterly winds along the eastern flank of the westward shifted Mongolian anticyclone transport more cold air from the higher

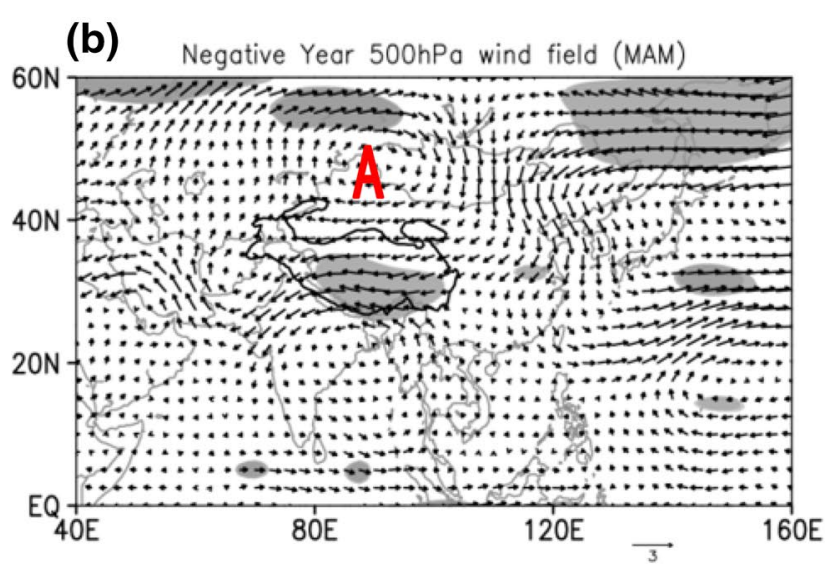

Fig. 7 The composite $500 \mathrm{hPa}$ wind field anomalies during the preceding season in strong and weak TPSM years 
(a)

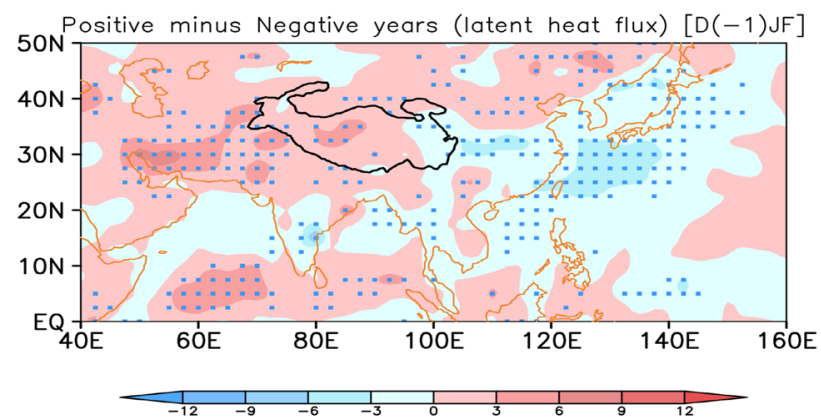

(c)
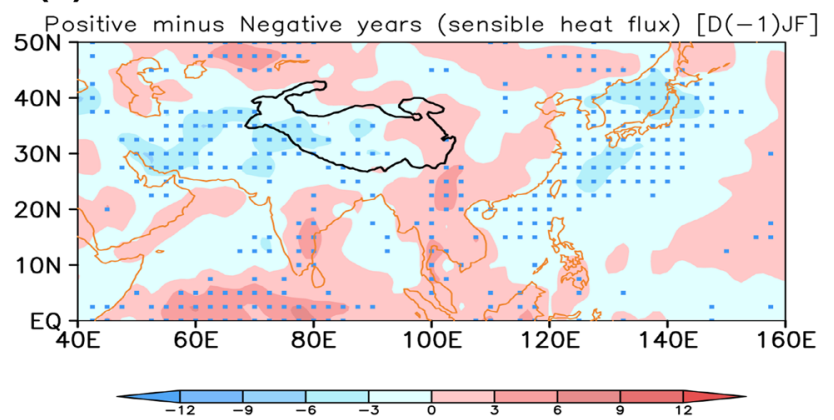

(e)

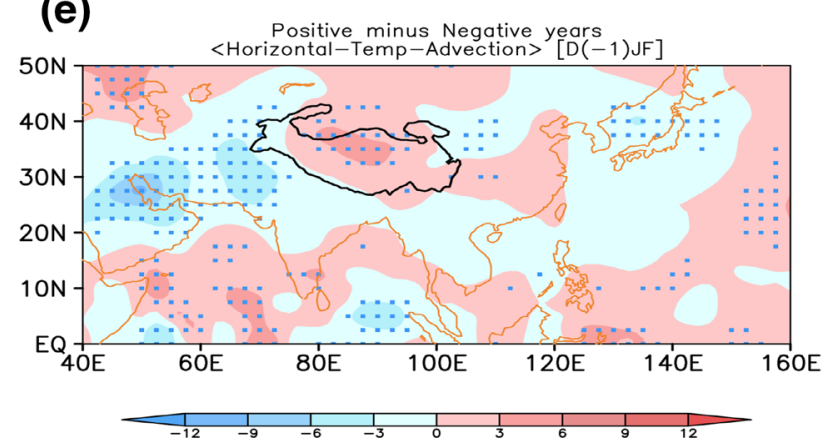

Fig. 8 The difference of latent heat flux ( $\mathrm{LH})$, sensible heat flux ( $\mathrm{SH})$ and horizontal temperature advection anomalies (contour interval 3) during the preceding season in strong and weak TPSM years, blue

latitudes, and, subsequently, cools the surface over the central and eastern TP (Fig. 9d). Insufficient SH during the preceding spring season occurs in conjunction with reduced soil heat content, which is also not favorable for convection supplying the condensational heating in summer. Therefore, the TPSM is weaker than normal.

The thermal forcing of TP is the key contributing factor for the formation and maintenance of the cyclonic circulation, which interacts with atmospheric circulation and climates of the surrounding areas (Ye and $\mathrm{Wu}$ 1998; Wu and Liu 2000). Duan et al. (2005) suggested that the abnormally strong sensible heating in the preceding season may influence the rainfall and atmospheric (b)

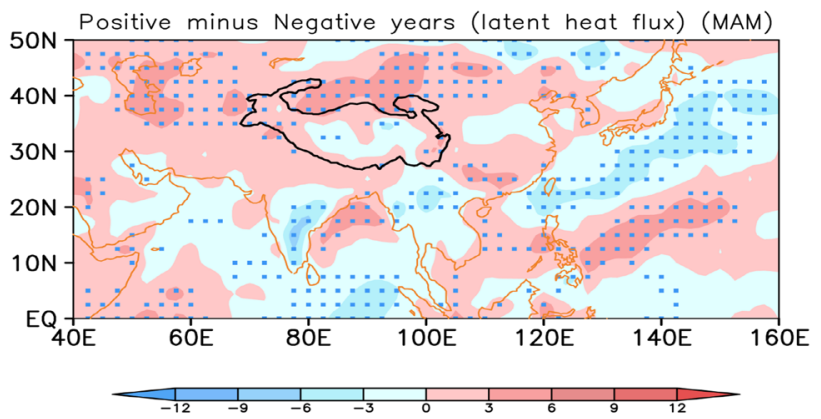

(d)
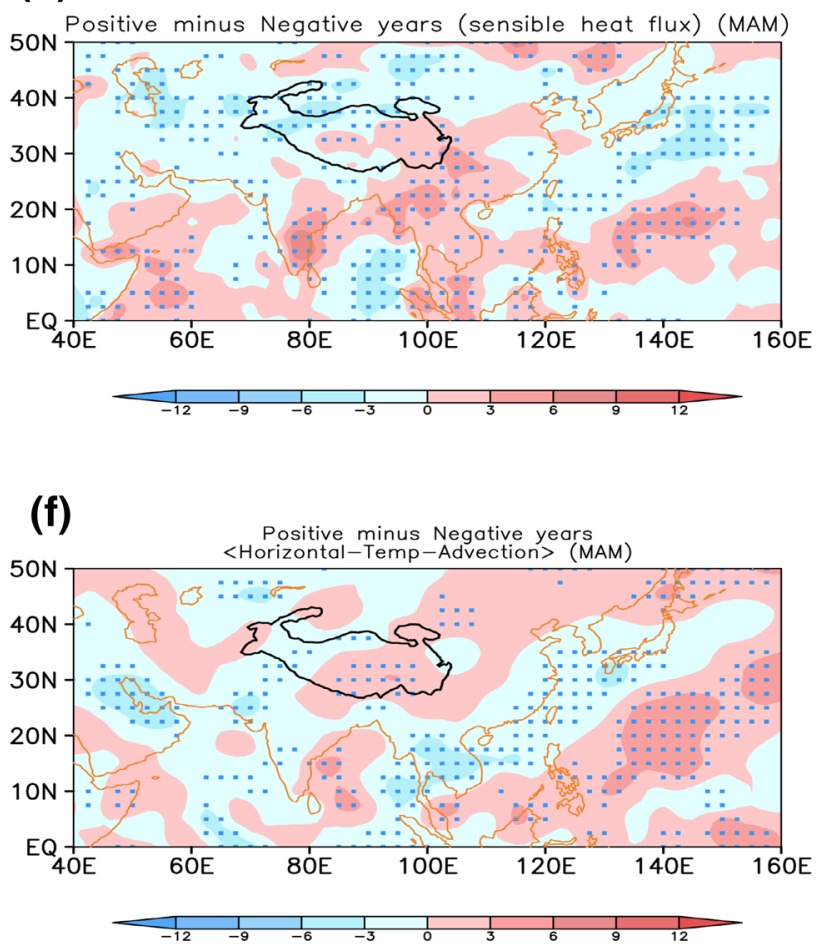

dots indicate statistically significant at the $90 \%$ confidence level. The solid curve indicates where the elevation exceeds $3000 \mathrm{~m}$

circulation in the following summer over the East Asian monsoon region. The study shows that the diabatic heating status over TP is well related to the TPSM. But, it should be noted that significant correlations and differences of composites do not necessarily indicate causality. Although our results show that the precipitation anomalies over northern India are associated with the diabatic heating variability over the TP, the dynamical mechanism is still unclear. The composite analysis indicates several possible clues of the generation of TPSM, and hence numerical experiments are required. However, the climate warming over TP during the last decades has been proved by many studies (Liu and Chen 2000; Duan et al. 2006; Duan and Wu 2008). Zhao and Moore (2004) noted that 

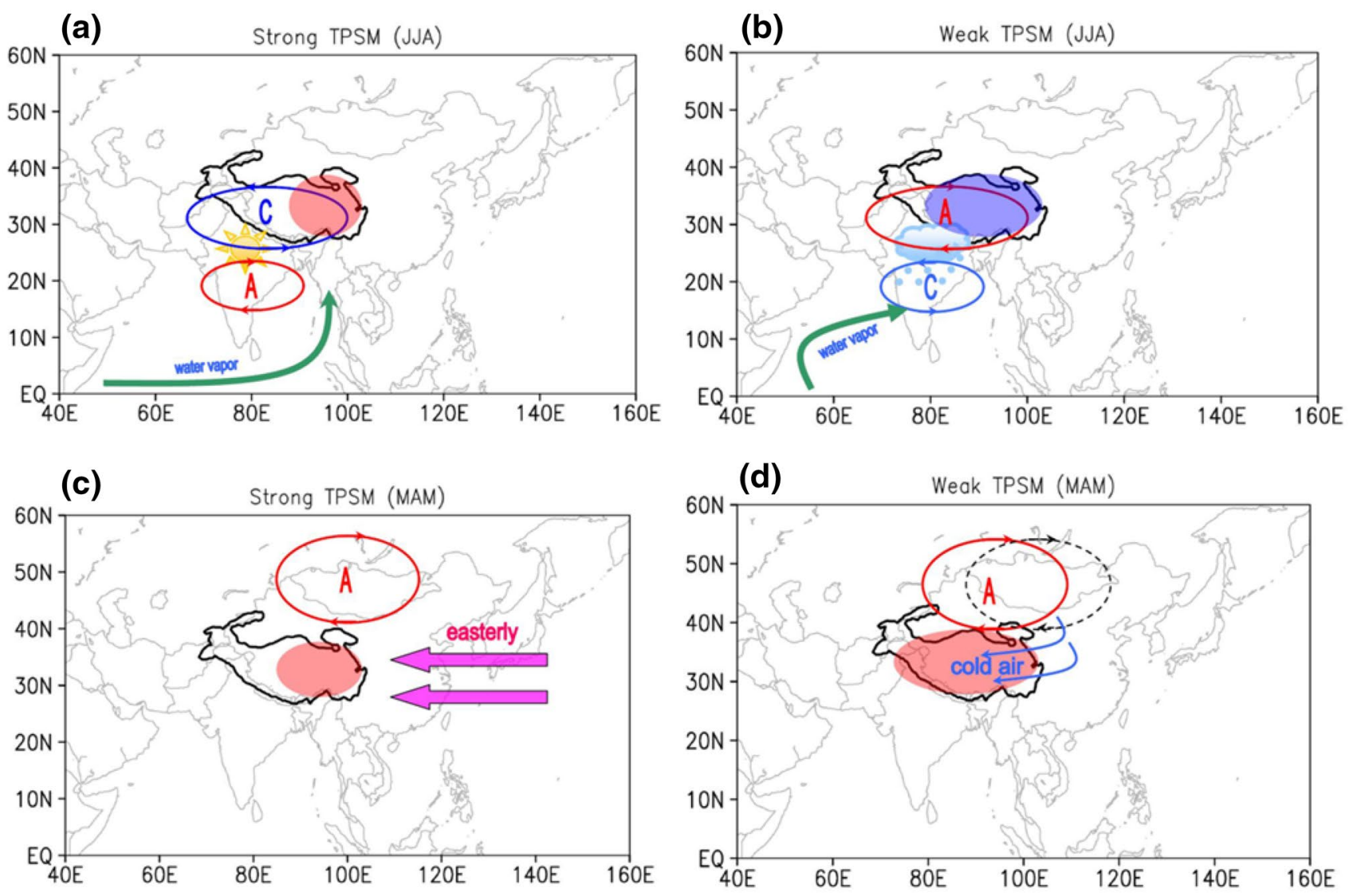

Fig. 9 Sketch map of circulation anomalies associated with TPSM. Red/blue shaded areas $(\mathbf{a}, \mathbf{b})$ indicate positive/negative diabatic heating anomalies. $A / C$ represents the anomalous anticyclone/cyclone. Green arrows indicate the moisture transporting. Red shaded areas (c, d) indicate positive surface sensible heating anomalies. Pink

the TPSM has weakened since 1970s, indicating that the interannual-interdecadal variations of TPSM. All these issues deserve further studies in the future. In any case, the present results obtained through this study are useful for understanding of atmospheric circulation over the TP, especially in terms of how the interannual variability of TPSM relates to Indian summer monsoon rainfall.

Acknowledgements Open access funding provided by Max Planck Society. We are grateful to Dr. Andrea Schneidereit for inspiring discussions about asymmetric heating pattern. This study acknowledges the support of the Jiangsu Planned Projects for Postdoctoral Research Funds (1402004B), the National Basic Research "973" Program of China (2012CB955200), the Max Planck Fellow Group, and the Priority Academic Program Development of Jiangsu Higher Education Institutions (PAPD).

Open Access This article is distributed under the terms of the Creative Commons Attribution 4.0 International License (http:// creativecommons.org/licenses/by/4.0/), which permits unrestricted use, distribution, and reproduction in any medium, provided you give appropriate credit to the original author(s) and the source, provide a

arrows indicate the easterly anomalies from the West Pacific. Blue arrows indicate the cold air intrusion from the westward shifted Mongolian anticyclone. The solid curve indicates where the elevation exceeds $3000 \mathrm{~m}$

link to the Creative Commons license, and indicate if changes were made.

\section{References}

Bai AJ, Li GP (2015) Climatology of monsoon precipitation over the Tibetan Plateau from 13-year TRMM observations. Theor Appl Climatol. doi:10.1007/s00704-015-1555-2

Bai HZ, Ma ZF, Dong WJ (2005) Relationship between QinghaiXizang Plateau region monsoon features and abnormal climate in China. J Appl Meteorol Sci 16(4):484-491 (Chinese)

Borth H, Tao H, Fraedrich K, Schneidereit A, Zhu XH (2016) Hydrological extremes in the Aksu-Tarim River Basin. Part II: Midlatitude dynamics. Clim Dyn 46, 2039-2050

Broccoli AJ, Manabe S (1992) The effects of orography on midlatitude Northern Hemisphere dry climates. J Clim 5:1181-1201

Chen GS, Liu Z, Kutzbach JE (2014) Reexamining the barrier effect of the Tibetan Plateau on the South Asian summer monsoon. Clim Past 10(3): 1269-1275

Compo GP, Whitaker JS, Sardeshmukh PD (2006) Feasibility of a 100 year reanalysis using only surface pressure data. Bull Am Meteorol Soc 87:175-190 
Davis RE (1976) Predictability of sea surface temperature and sea level pressure anomalies over the North Pacific Ocean. J Phys Oceanogr 6(3):249-266

Duan AM, Wu GX (2005) Role of the Tibetan Plateau thermal forcing in the summer climate patterns over subtropical Asia. Clim Dyn 24: 793-807

Duan AM, Wu GX (2008) Weakening trend in the atmospheric heat source over the Tibetan Plateau during recent decades. Part I: Observations. J Clim 21(13):3149-3164

Duan AM, Liu YM, Wu GX (2005) Heating status of the Tibetan Plateau from April to June and rainfall and atmospheric circulation anomaly over East Asia in midsummer. Sci China D 48(2):250-257

Duan AM, Wu GX, Zhang Q, Liu YM (2006) New proofs of the recent climate warming over the Tibetan Plateau as a result of the increasing greenhouse gases emissions. Chin Sci Bull 51(11):1396-1400

Flohn H (1957) Large-scale aspects of the "summer monsoon" in South and East Asia. J Meteorol Soc Jpn 75:180-186

Flohn H (1968) Contributions to a meteorology of the Tibetan highlands. Atmospheric science papers, no. 130, Fort Collins: Colorado State University Press, pp. 1-120

Harris I, Jones PD, Osborn TJ, Lister DH (2014) Updated high-resolution grids of monthly climatic observations-the CRU TS3.10 Dataset. Int J Climatol 34:623-642

Holton JR (1992) An introduction to dynamic meteorology, 3rd edn. Academic Press, San Diego

Hoskins BJ, Karoly DJ (1981) The steady linear response of a spherical atmosphere to thermal and orographic forcing. J Atmos Sci 38:1179-1196

Kalnay E, Kanamitsu M, Kistler R et al (1996) The NCEP/NCAR 40-year reanalysis project. Bull Am Meteorol Soc 77:437-471

Kripalani RH, Kulkarni A (1999) Climatology and variability of historical Soviet snow depth data: some new perspectives in snow: Indian monsoon teleconnections. Clim Dyn 15(6):475-489

Liu XD (1999) Influences of Qinghai-Xizang (Tibet) plateau uplift on the atmospheric circulation, global climate and environment changes. Plateau Meteorol 18:321-332 (Chinese)

Liu XD, Chen BD (2000) Climatic warming in the Tibetan Plateau during recent decades. Int J Climatol 20(14):1729-1742

Liu YM, Wu GX, Liu H, Liu P (2001) Condensation heating of the Asian summer monsoon and the subtropical anticyclone in the Eastern Hemisphere. Clim Dyn 17:327-338

Liu YM, Wu GX, Ren RC (2004) Relationship between the subtropical anticyclone and diabatic heating. J Clim 17:682-698

Mitchell TD, Jones PD (2005) An improved method of constructing a database of monthly climate observations and associated highresolution grids. Int J Climatol 25:693-712

Nitta T (1983) Observational study of heat sources over the eastern Tibetan Plateau during the summer monsoon. J Meteorol Soc Jpn 61(4):590-605

Park HS, Xie SP, Son SW (2013) Poleward stationary eddy heat transport by the Tibetan Plateau and equatorward shift of westerlies during northern winter. J Clim 70(10):3288-3301

Parthasarathy B, Kumar KR, Kothawale DR (1992) Indian summer monsoon rainfall indices, 1871-1990. Meteorol Mag 121:174-186

Parthasarathy B, Kumar KR, Munot AA (1993) Homogeneous Indian monsoon rainfall: variability and prediction. Proc Indian Acad Sci Earth Planet Sci 102(1):121-155

Plumb RA (1985) On the three-dimensional propagation of stationary waves. J Atmos Sci 42:217-229

Reiter ER, Gao DY (1982) Heating of the Tibet plateau and movements of the South Asian high during spring. Mon Weather Rev 110(11):1694-1711
Saito K, Yasunari T, Cohen J (2004) Changes in the sub-decadal covariability between Northern Hemisphere snow cover and the general circulation of the atmosphere. Int J Climatol 24(1):33-44

Schneider T, Bordoni S (2008) Eddy-mediated regime transitions in the seasonal cycle of a Hadley circulation and implications for monsoon dynamics. J Atmos Sci 65:915-934

Tang MC, Reiter ER (1984) Plateau monsoon of the northern hemisphere: a comparison between North America and Tibet. Mon Weather Rev 112:617-637

Tang MC, Shen ZB, Chen YY (1979) On climatic characteristics of the Xizang plateau monsoon. Acta Geogr Sin 34:33-42 (Chinese)

Tang H, Micheels A, Eronen JT, Ahrens B, Fortelius M (2013) Asynchronous responses of East Asian and Indian summer monsoons to mountain uplift shown by regional climate modelling experiments. Clim Dyn 40:1531-1549

Tao H, Borth H, Fraedrich K, Schneidereit A, Zhu XH (2016) Hydrological extremes in the Aksu-Tarim River Basin. Part I: Climatology and regime shift. Clim Dyn 46:2028-2037

Tian L, Masson-Delmotte V, Stievenard M, Yao T, Jouzel J (2001) Tibetan Plateau summer monsoon northward extent revealed by measurements of water stable isotopes. J Geophys Res 106(D22):28081-28088

Wang ZQ, Duan AM, Wu GX (2014) Time-lagged impact of spring sensible heat over the Tibetan Plateau on the summer rainfall anomaly in East China: case studies using the WRF model. Clim Dyn 42:2885-2898

Whitaker JS, Compo GP, Wei X, Hamill TM (2004) Reanalysis without radiosondes using ensemble data assimilation. Mon Weather Rev 132:1190-1200

Wu GX (1984) The nonlinear response of the atmosphere to large-scale mechanical and thermal forcing. J Atmos Sci 41(16):2456-2476

Wu GX, Liu YM (2000) Thermal adaptation, overshooting, dispersion and subtropical anticyclone. I. Thermal adaptation and overshooting. Chin J Atmos 24:433-446

Wu GX, Liu YM (2003) Summertime quadruplet heating pattern in the subtropics and the associated atmospheric circulation. Geophys Res Lett 30:1201

Wu GX, Zhang YS (1998) Tibetan Plateau forcing and the timing of the monsoon onset over South Asia and the South China Sea. Mon Weather Rev 126:913-927

Wu GX, Liu YM, Wang TM, Wan RJ, Liu X, Li WP, Wang ZZ, Zhang Q, Duan AM, Liang XY (2007) The influence of mechanical and thermal forcing by the Tibetan Plateau on Asian climate. J Hydrometeorol 8:770-789

Wu ZW, Jiang ZH, Li JP, Zhong SS, Wang LJ (2012a) Possible association of the western Tibetan Plateau snow cover with the decadal to interdecadal variations of Northern China heatwave frequency. Clim Dyn 39:2393-2402

Wu GX, Liu YM, He B, Bao Q, Duan AM, Jin FF (2012b) Thermal controls on the Asian summer monsoon. Sci Rep 2:404. doi:10.1038/srep00404

Wu ZW, Zhang P, Chen H, and Li Y (2016) Can the Tibetan Plateau snow cover influence the interannual variations of Eurasian heat wave frequency? Clim Dyn 46(11): 3405-3417, doi:10.1007/ s00382-015-2775-y

Yanai M, Li CF (1994) Mechanism of heating and the boundary layer over the Tibetan Plateau. Mon Weather Rev 122:305-323

Yanai M, Esbensen S, Chu JH (1973) Determination of bulk properties of tropical cloud clusters from large-scale heat and moisture budgets. J Atmos Sci 30(4):611-627

Yanai M, Li CF, Song ZS (1992) Seasonal heating of the Tibetan Plateau and its effects on the evolution of the Asian summer monsoon. J Meteor Soc Japan 70:319-351 
Ye DZ, Gao YX (1979) Climatology of Qinghai-Xizang (Tibetan) Plateau. Science Press, Beijing, p 279

Ye DZ, Wu GX (1998) The role of the heat source of the Tibetan Plateau in the general circulation. Meteorol Atmos Phys 67:181-198

Yeh TC (1950) The circulation of the high troposphere over China in the winter of 1945-46. Tellus A 2(3):173-183

Yeh TC, Luo SW, Zhu BZ (1957) The structure of stream fields over the Tibetan Plateau and surrounding areas and the balance of quantity of heat in the troposphere. Acta Meteorol Sin 28(2):108-121 (Chinese)

Zhao P, Chen LX (2001) Interannual variability of atmospheric heat source/sink over the Qinghai-Xizang (Tibetan) Plateau and its relation to circulation. Adv Atmos Sci 18:106-116
Zhao HX, Moore GWK (2004) On the relationship between Tibetan snow cover, the Tibetan Plateau monsoon and the Indian summer monsoon. Geophys Res Lett 31:L14204. doi:10.1029/200 4GL020040

Zhao Y, Huang AA, Zhou Y, Yang Q (2015) The impacts of the summer plateau monsoon over the Tibetan Plateau on the rainfall in the Tarim Basin, China. Theor Appl Climatol. doi:10.1007/ s00704-015-1576-x 